\title{
ENERGY TRANSFER WITH SOJI TSUCHIYA
}

Encounters with Soji Tsuchiya are always exciting and enjoyable. We met at the first Gordon Conference on Molecular Energy Transfer (COMET) about one quarter of a century ago at Proctor Academy in New Hampshire. It was an exciting time for both of us. Soji's beautiful work on the mechanisms of electronic-to-vibration energy transfer in sodium and mercury collisions with diatomics established him as an international leader in energy transfer. His work was of special interest to me as my wife and I had tried unsuccessfully to use mercury to pump a $\mathrm{CO}$ vibrational laser several years before. Soji was quite interested in experiments reported by George Flynn, Ali Javan, Jim Yardley and me using the $\mathrm{CO}_{2}$ laser to study vibration-to-vibration transfer. This approach was really easy compared to the shock tube experiments which Soji had done to observe vibrational energy transfer. The combination of his work and his lively outgoing personality made Soji a truly distinguished one-man delegation from Japan at a relatively young age. He was immediately included in the core group responsible for planning future COMET conferences. Soji's time in Si Bauer's lab at Cornell had given him a good understanding of the lack of reserve typical of scientific discussions in the U.S. and an opportunity to develop his talents as a scientific ambassador. He appeared quite comfortable in vigorous debate as well as in non-scientific conversation. The breadth of his smile and the depth of his laugh makes me suspect that his enjoyment of this activity was the product of something much deeper than skilled statesmanship.

Soji organized a Japan-U.S. seminar on molecular energy transfer in the early seventies which was the first of many scientifically profitable and culturally enjoyable visits to Japan. Many of the names from papers in vibrational spectroscopy became faces for me and my American colleagues. I met K. Takayanagi whose paper on the theory of rotational energy transfer was the basis of my Ph.D. prelim proposal. Soji was doing masterful work on vibration-to-vibration energy transfer using data obtained over wide temperature ranges to establish fundamental mechanisms. He also helped me begin to appreciate the customs, art, and architecture of Japan. Consequently, I am able to snatch occasional moments of peaceful tranquillity in contemplation of an harmonious garden or temple. Since then, we have shared discussions on many topics such as ir multiphoton dissociation or rates of radical reactions and enjoyed dinners in many places. I have spent part of a year as visiting professor at the Institute for Molecular Sciences and made many other shorter visits to Japan. Soji's recent work on the spectroscopy of $\mathrm{NO}_{2}$ vibrational levels near the 
threshold for dissociation has provided a landmark fundamental test of unimolecular reaction rate theory and the most recent overlap of our scientific interests.

Soji Tsuchiya is a remarkably creative and resourceful scientist. He is an international leader in energy transfer and reaction dynamics research. He is also an exceptional human being, teacher and friend. He is one of the people who makes scientific research an exciting, challenging, pleasurable and truly international activity. We clearly can expect more excitement and surprises in this next phase of his career.

C. B. Moore, Department of Chemistry, University of California, Berkeley, CA 94720, U.S.A. 